\title{
Rectus sheath block for postoperative pain relief in children undergoing major abdominal surgery
}

\author{
Dilek Özcengiz ${ }^{1 *}$, Beyza Tekin Bayrak², Ersel GÜLEÇ ${ }^{1}$, Murat Alkan³ ${ }^{3}$ Yasemin GÜNEŞ1
}

\begin{abstract}
Background: Regional anaesthetic techniques in children has become increasingly popular and used to provide analgesia for umbilical and epigastric hernia repair, laparoscopic surgery, pyloromyotomy and other small midline incisions. Our objective was to assess the efficacy and side effects of the rectus sheath block than a control group that received intravenous tramadol, for pain control after major abdominal surgery in children.

Methods: Sixty children aged 1-15 years who underwent laparotomy via transverse incision were recruited for this randomised study. Patients were allocated randomly into two groups: group R (n: 30) patients who had rectus sheath block with levobupivacaine $0.25 \%$ and group $\mathrm{T}$ (n: 30 ), control patients who received iv tramadol with local saline injections into rectus sheath. CHEOPS and sedation scores were noted after the injection of local anesthetic at 5, 15, 30, 60 minutes and 2, 6, 12, 24 hours.

Results: The mean total amounts of tramadol used by the levobupivacaine and the normal saline groups in the first $24 \mathrm{~h}$ were 0.95 $\mathrm{mg} / \mathrm{kg}$ and $4.07 \mathrm{mg} / \mathrm{kg}$. There was no significant difference between the groups in CHEOPS pain score and sedation score. The incidence of were lower in group R than in Group T.

Conclusions: In terms of postoperative nausea and vomiting and analgesic consumption and the duration of analgesia the rectus sheath block has superiority to intravenous tramadol in children undergoing major abdominal surgery.
\end{abstract}

Key words: Child, Postoperative Care, Rectus sheath

\section{Introduction}

The rectus sheath block, a regional anesthetic technique first described in 1899 by Schleich [1], may offer improved pain management following umbilical hernia repair. Interest in the block has been renewed following reports of its analgesic efficacy in adults undergoing laparoscopy and in children for para-umbilical and umbilical hernia repair [2-4]. Studies in adults and children have compared the rectus sheath block with opioids alone for analgesia after laparoscopic surgery, showing favorable results $[2,5]$. It was successfully used in chronic pain management of pediatric abdominal wall pain [6].

Since this regional anaesthetic technique has become increasingly popular and has been used to provide analgesia for umbilical and epigastric hernia repair, laparoscopic surgery, pyloromyotomy and other small midline incisions. Two techniques have been described in children [3,4]. Both of these techniques purposed to block the terminal branches of 9th, 10th and 11th intercostal nerve within the rectus sheath in a different way. It was reported that, per-operative rectus sheath infiltration obtains an effective analgesia and postoperative analgesia requirement are reduced significantly in abdominoplasty, in adult patients[7].

\footnotetext{
*Correspondence: dilekozcengiz@gmail.com

${ }^{1}$ Cukurova University Faculty of Medicine,

Department of Anesthesiology Adana-Turkey.

Full list of Author information is available at the end of the Article
}

We are not aware of any literature describing the use of rectus sheath blocks for major abdominal surgery in children.

The aim of this study was to evaluate the efficacy of the rectus sheath block for pain control after major abdominal surgery in children by comparing with a control group that received intravenous (iv) tramadol.

\section{Methods}

This prospective study was carried out after approving of our local research ethics committee and informed parental consent. Sixty children aged 1-15 years who underwent laparotomy via transverse incision were recruited for this randomised study. Patients were allocated randomly into two groups: group $R$ (n: 30) patients who had rectus sheath block with levobupivacaine $0.25 \%$ and group $T(n: 30)$, control patients who received tramadol with local saline injections into rectus sheath. In group R eight patients needed analgesic drug in the first thirty minutes in recovery room. These patients were excluded so these results were accepted insufficient rectus sheath block.

\section{Anesthetic Technique}

No premedication was administered. After general anesthesia was induced with $8 \%$ sevoflurane via facemask, an intravenous cannula and after administering i.v $0.1 \mathrm{mg} / \mathrm{kg}$ vecuronium bromide an appropriate size endotracheal tube were placed. Anesthesia was maintained with $2 \%$ sevoflurane, $50 \%$ oxygen 
and $50 \%$ nitrous oxide. Any supplement analgesic agent for postoperative analgesia was not used intraoperatively in two groups. Patients were ventilated to normocapnia throughout the surgical procedure. Standart intraoperative monitoring included ECG and heart rate, pulse oximetry, automatic non-invasive blood pressure and end-tidal carbondioxide concentration. At the conclusion of surgery, muscle relaxation was reversed by neostigmine $50 \mu \mathrm{g} / \mathrm{kg}$ and atropine sulfate $15 \mu \mathrm{g} / \mathrm{kg}$.

\section{Surgical technique}

All operations were performed via transverse incision. At the end of the procedure before closure under direct vision, levobupivacaine $0.25 \%$ was bilaterally injected as a total of $0.2 \mathrm{ml} / \mathrm{kg}$ divided between the two sides and between the posterior aspect of the rectus muscle and its fascia in group $\mathrm{R}$ and $0.2 \mathrm{ml} / \mathrm{kg}$ saline solution in group T. Fortyfive minutes before the end of the surgery, tramadol $2 \mathrm{mg} / \mathrm{kg}$ was given intravenous as only single dose to all patients in group T. Saline was administered as placebo in Group R, intravenously.

\section{Study parameters}

Postoperatively, an anesthesiologist who was blinded to the analgesic technique recorded the hemodynamic parameters and the Children's Hospital of Eastern Ontario Pain Scale (CHEOPS) [8] in the post-anesthesia recovery room and in the day care unit until discharge from the hospital. CHEOPS and sedation scores were noted after the injection of local anesthetic at 5, 15, 30, 60 minutes and 2, 6, 12, 24 hours. Rescue analgesia, consisting of intravenous tramadol $1 \mathrm{mg} / \mathrm{kg}$ was administered for a CHEOPS score of $\geq 7$. Total tramadol dose was tallied. The maximum dose of tramadol was limited to $5 \mathrm{mg} / \mathrm{kg} /$ day. Intravenously morphine $0.1 \mathrm{mg} / \mathrm{kg}$ was planned to be added if tramadol was not enough. Ondansetron $0.1 \mathrm{mg} / \mathrm{kg}$ was used for cases with nausea or vomiting. Analgesic requirement, parents satisfactions, nausea and vomiting were all recorded. The duration of analgesia was defined as the time of first analgesic requirement.

\section{Statistical methods}

Based on a power of $95 \%$ and to obtain a statistical significance of $p<0.05$ for $30 \%$ of reducing tramadol consumption, the minimum number of patients needed was 30 in each group. Data were presented as mean ( \pm standard deviation). Data in the two groups were compared using the unpaired t test. Statistical analysis was performed using Statistical Package for the Social Sciences (SPSS) program. GPower3.01.0 program was used for power analysis [9]. A $p$-value of $<0.05$ was considered statistically significant.

\section{Results}

Fifty two patients were evaluated in this study. Eight patients in group $\mathrm{R}$, who received the analgesic drugs in recovery room first 30 minutes after operation were excluded from the study. Patient characteristics and surgical variables in the two groups were closely comparable (Table 1). The types of surgery to be performed in each group were demonstrated in Table 2.The mean total amounts of tramadol used by the levobupivacaine and the normal saline groups in the first $24 \mathrm{~h}$ were $0.95 \mathrm{mg} / \mathrm{kg}$ and $4.07 \mathrm{mg} / \mathrm{kg}$, respectively $(P=0.01, a=0.05$, power $=0.99$ ). There was no significant difference between the groups in CHEOPS pain score (Table 3 ) and sedation score.

The duration of analgesia was statistically longer in group $R$ than group $T(p<0.001)$. The score of parents satisfaction was higher in group $R(P=0.003, a=0.05$, power $=0.75)$ (Table 4). Eleven patients had nausea and one of them vomited and two patients had nausea in group T and Group $R$, respectively ( $p=0.013$ ) (Table 3 ). No patient had any other side effect, such as respiratory depression, hypotension, bradycardia, infection, deep sedation, allergic reaction, related to levobupivacaine or tramadol and rectus sheath block.

Table 1. Demographic values and surgical variables in groups

\begin{tabular}{lcc}
\hline & Group R (n=22) & $\begin{array}{c}\text { Group T } \\
(\mathbf{n = 3 0})\end{array}$ \\
\hline Age (years) & $6.8 \pm 3.4$ & $6.0 \pm 4.5$ \\
Weight (kg) & $20.5 \pm 9.3$ & $21.0 \pm 13.2$ \\
Duration of surgery $(\mathrm{min})$ & $130 \pm 40$ & $139 \pm 44$ \\
\hline
\end{tabular}

Table 2. The distribution of the patients in each group according to the surgical type.

\begin{tabular}{lcc}
\hline The type of surgery & Group R(n=22) & $\begin{array}{c}\text { Group T } \\
(\mathbf{n}=\mathbf{3 0})\end{array}$ \\
\hline Ileostomy & 5 & 6 \\
Malrotation & 2 & 5 \\
Intestinal obstruction & 4 & 7 \\
$\begin{array}{l}\text { Intraabdominal tumour } \\
\text { resection }\end{array}$ & 11 & 12 \\
\hline
\end{tabular}

Table 3. Postoperatively CHEOPS values in groups.

\begin{tabular}{lcc}
\hline & Group R(n=22) & $\begin{array}{c}\text { Group T } \\
(\mathbf{n}=\mathbf{3 0})\end{array}$ \\
\hline $5 \mathrm{~min}$ & $6.4 \pm 2.1$ & $6.3 \pm 1.6$ \\
$10 \mathrm{~min}$ & $6.3 \pm 1.8$ & $6.4 \pm 1.6$ \\
$15 \mathrm{~min}$ & $6.2 \pm 1.2$ & $6,3 \pm 1,5$ \\
$30 \mathrm{~min}$ & $6.0 \pm 0.8$ & $6.2 \pm 1.1$ \\
$60 \mathrm{~min}$ & $6.1 \pm 1.0$ & $6.0 \pm 0.4$ \\
2 hour & $6.3 \pm 1.4$ & $6.4 \pm 1.2$ \\
6 hour & $6,8 \pm 1,4$ & $6.5 \pm 1.5$ \\
12 hour & $6.3 \pm 1.2$ & $6.1 \pm 1.1$ \\
24 hour & $5.8 \pm 1.0$ & $5.5 \pm 0.6$ \\
\hline
\end{tabular}


Table 4. Duration of the analgesia, analgesic requirements, and side effects

\begin{tabular}{lccc}
\hline & $\begin{array}{c}\text { Group R } \\
(\mathbf{n}=\mathbf{2 2})\end{array}$ & $\begin{array}{c}\text { Group T } \\
(\mathbf{n}=\mathbf{3 0})\end{array}$ & $\mathbf{P}$ \\
\hline $\begin{array}{l}\text { Duration of analgesia } \\
(\text { min) }\end{array}$ & $900 \pm 553$ & $133 \pm 90$ & $\mathrm{P}=0.000$ \\
$\begin{array}{l}\text { Tramadol used (mg/kg) } \\
\text { Nausea and vomiting } \\
\text { (number of the patients) }\end{array}$ & $2.95 \pm 1.21$ & $4.07 \pm 0.83$ & $\mathrm{P}=0.01$ \\
Parents satisfaction & $1.22 \pm 0.43$ & $12(40 \%)$ & $\mathrm{P}=0.013$ \\
\hline
\end{tabular}

\section{Discussion}

This study compared the rectus sheath block with iv tramadol in children undergoing major abdominal surgery. Our results showed that per-operative rectus sheath block reduced postoperative tramadol consumption.

In their study, Anwar et al. [7] reported that a standard transverse incision abdominoplasty was performed with plication of the rectus sheath. After plication, before closure under direct vision, a mixture of bupivacaine $2 \mathrm{ml} / \mathrm{kg}$ and clonidine $1 \mu \mathrm{g} / \mathrm{kg}$ made to $60 \mathrm{ml}$ with normal saline was injected: $30 \mathrm{ml}$ to each sheath. They reported that by using this technique, the requirements for postoperative analgesia were reduced significantly in abdominoplasty patients. In adults, the rectus sheath block has been shown to improve patient comfort after laparoscopic surgery, suggesting that it might be an alternative to epidural anesthesia for some surgical procedures [2]. Although regional anesthetic techniques are commonly used for postoperative pain control in pediatric anesthesia, there were very few data about rectus sheath block.

Isaac et al. [5] compared the rectus sheath block with infiltration of local anesthetic into the surgical incision in children undergoing repair of umbilical hernia. Their results suggested that postoperative pain control, assessed using postoperative morphine consumption as the primary outcome, did not differ significantly between the two groups.

The key to success in regional anaesthesia is to place the correct dose of local anaesthetic in the right place. Willschke and Bösenberg [10] reported that successful rectus sheath blocks were achieved in all children using bilateral placement of levobupivacaine $0.25 \% 0.1 \mathrm{ml} \mathrm{kg}^{-1}$. This dose and volume of local anesthetic was similar in our study. The rectus sheath block, performed under direct vision, was performed in most of patients. The dose and volume of levobupivacaine was sufficient in the most of patients in our study.

The rectus sheath block in combination with ilio-inguinal nerve blocks has been described for abdominal gynaecological procedures in adults [11]. Hussein et al. [12] reported to routinely perform combined bilateral ilio-inguinal and rectus sheath blocks for elective gynaecological operations involving a Pfannensteil incision. They suggested that the block obtained very effective analgesia and no patient needed any supplementary analgesic drug. However, Cornish et al.[13] reported their rationale for initial results using catheters implanted in the posterior aspect of the rectus sheath for upper abdominal surgery. At the end of surgery, local anesthetic, $20 \mathrm{~mL}$ of solution (e.g. bupivacaine $0.25 \%+1: 400000$ adrenalin) through each catheter, was injected in this study and obtained effective analgesia with using this system. In our study, the insicion was bigger than umblical hernia incision. It can be explained why some patients had pain and the rectus sheath block failed. Courreges et al. [4] described a new technique to provide analgesia in 11 children undergoing the umbilical hernia repair: the para-umbilical block. In this paper, the authors stated that the course of the cutaneous branch of the 10th intercostal nerve is variable. Sometimes, it lies between the rectus muscle and the posterior wall of its sheath, but up to $30 \%$ of cases, the cutaneous branch of the 10th intercostal nerve could arise before the rectus sheath and run above the anterior wall of the rectus sheath in the subcutaneous space. They suggested that infiltration by LA in the middle of the rectus muscle, both above and below the anterior wall of the sheath would result in spread around the anterior cutaneous branches whatever the anatomical variation.

Whether the efficacy of the rectus sheath block would have been enhanced had we used a faster acting local anesthetic or performed the block before surgery is speculative. Despite extensive study, the efficacy of preemptive analgesia is controversial [14-16], although epidural analgesia, local infiltration, and nonsteroidal anti-inflammatory drugs have shown promise as preemptive strategies [15]. By inference, the use of the rectus sheath block prior to the start of surgery may reduce sevoflurane consumption during surgery.

In summary, our results showed that the rectus sheath block with $0.1 \mathrm{ml} / \mathrm{kg} 0.25 \%$ levobupivacaine provided long acting analgesia compared to intravenous tramadol. Rectus sheath block reduced tramadol consumption and may be used for postoperative pain management in children undergoing major abdominal surgery without any complication.

\section{Competing interests}

The Authors declare that they have no competing interests.

\section{Author information}

${ }^{2}$ Gaziantep University Faculty of Medicine Department of Anesthesiology, Turkey.

${ }^{3}$ Çukurova University Faculty of Medicine Department of Pediatric Surgery, Turkey.

\section{Publications history}

Editor: Maria Matuszczak,

The University of Texas Medical School, USA.

Received: 19-Jan-2012 Revised: 09-Feb-2012

Re-Revised: 03-May-2012 Accepted: 28-May-2012

Published: 11-June-2012 


\section{References}

1. Schleich DL: Schmerzlose operationen, 4th edn. Berlin: Springer, 1899; 240-258.

2. Smith BE, Suchak M, Siggins D, Challands J: Rectus sheath block for diagnostic laparoscopy. Anaesthesia 1988; 43;(11.);947-8. | PubMed

3. Ferguson $\mathrm{S}$, Thomas $\mathrm{V}$, Lewis I: The rectus sheath block in paediatric anaesthesia: new indications for an old technique? Paediatr Anaesth 1996; 6;(6.);463-6. | PubMed

4. Courreges P, Poddevin F, Lecoutre D: Para-umbilical block: a new concept for regional anaesthesia in children. Paediatr Anaesth 1997; 7;(3.);211-4. | Article | PubMed

5. Isaac LA, McEwen J, Hayes JA, Crawford MW: A pilot study of the rectus sheath block for pain control after umbilical hernia repair. Paediatr Anaesth 2006; 16;(4.);406-9. | Article | PubMed

6. Skinner AV, Lauder GR: Rectus sheath block: successful use in the chronic pain management of pediatric abdominal wall pain. Paediatr Anaesth 2007; 17;(12.);1203-11. | Article | PubMed

7. Anwar MU, Rawlins J, Baker P, Fairbrass M, Foo IT: Per-operative infiltration of the rectus sheath in abdominoplasty. Aesthetic Plast Surg 2008; 32;(1.);178. | Article | PubMed

8. McGrath PJ, Johnson G, Goodman JT, Schillinger J, Dunn J et al.: The CHEOPS: a behavioural scale to measure postoperative pain in children. Advances in Pain Research and Therapy 1985; 9: 395-402.

9. Faul F, Erdfelder E, Lang AG, Buchner A: G*Power 3: a flexible statistical power analysis program for the social, behavioral, and biomedical sciences. Behav Res Methods 2007; 39;(2.);175-91. | PubMed

10. Willschke $H$, Bosenberg A, Marhofer P, Johnston S, Kettner SC, Wanzel $O$, et al.: Ultrasonography-guided rectus sheath block in paediatric anaesthesia--a new approach to an old technique. Br J Anaesth 2006; 97;(2.);244-9. | Article | PubMed

11. Yentis SM, Hills-Wright P, Potparic O: Development and evaluation of combined rectus sheath and ilioinguinal blocks for abdominal gynaecological surgery. Anaesthesia 1999; 54;(5.);475-9. | Article | PubMed

12. Husain NK, Ravalia A: Ultrasound-guided ilio-inguinal and rectus sheath nerve blocks. Anaesthesia 2006; 61;(11.);1126. | Article | PubMed

13. Cornish $P$, Deacon A: Rectus sheath catheters for continuous analgesia after upper abdominal surgery. ANZ J Surg 2007; 77;(1-2.);84. | Article | PubMed

14. Moiniche $S$, Kehlet $H$, Dahl JB: A qualitative and quantitative systematic review of preemptive analgesia for postoperative pain relief: the role of timing of analgesia. Anesthesiology 2002; 96;(3.);725-41. | PubMed

15. McCartney $C J$, Sinha A, Katz J: A qualitative systematic review of the role of $\mathrm{N}$-methyl-D-aspartate receptor antagonists in preventive analgesia. Anesth Analg 2004; 98;(5.);1385-400, table of contents. | Article | PubMed
16. Ong CK, Lirk P, Seymour RA, Jenkins BJ: The efficacy of preemptive analgesia for acute postoperative pain management: a meta-analysis. Anesth Analg 2005; 100;(3.);757-73, table of contents. | Article | PubMed

\section{Citation:}

Özcengiz D, Bayrak B T, GüLeç E, Alkan M and GüNeå Y: Rectus sheath block for postoperative pain relief in children undergoing major abdominal surgery. journal of Anesthesiology and Clinical Science 2012, 1:5. http://dx.doi.org/10.7243/2049-9752-1-5 